\title{
Analysis on Women's Suicide and Government Governance in the Bottom Society of Beijing in the Early Republic of China (1912-1928)
}

\author{
Congling Sun
}

\author{
School of History, Capital Normal University, Beijing 100048, China
}

\begin{abstract}
The marital life of women at the bottom of society was very worrying in the early Republic of China in Beijing, with high suicide phenomenon. The main causes are poverty, couple conflict, contradiction between mother-in-law and daughter-in-law, as well as the persecution of traditional concepts such as "men are superior to women", and "preserve chastity after the death of the husband". Under the overall layout of building a modern country, Beijing local government tries to bring marriage crisis and women's suicide into the scope of social intervention on police and government agencies, but there is always a huge tension between policy plan and concrete practice.
\end{abstract}

Keywords: Early Republic of China, The bottom society of Beijing, Women's suicide, Beijing Municipal Public Security Bureau.

\section{Introduction: Starting from A Case}

Such a case is recorded in the archives of the Beijing Police Department preserved in the Beijing Archives. At 2 o'clock on the night of August 25, 1918, when the patrol officer Dong Runqian of the second branch of the Central Police Department of the Capital Police Department patrolled to Miaoerhu, he suddenly discovered that the door of No. 2 courtyard was wide open, and the groaning of women Zhang Wang was heard in the courtyard. He immediately checked the house and found that Zhang Wang was lying on his back on the Kang, with a wound on the lower right side of his neck, which had been bandaged with medicated cloth. According to his husband Zhang Mingshan's confession, he and his wife are addicted to cigarettes and morphine injections, and are now taking drugs to quit. That night, because there were not many smoking cessation drugs in the family, he refused his wife's request for medication, which caused the couple to quarrel. Angrily, Zhang Wang tried to commit suicide and scratched his neck with a razor. After Police Officer Dong confirmed Zhang Wang's vital signs, and the guards sent her to the hospital for emergency treatment, and took Zhang Mingshan back to the police station for further investigation[1]. In Dong Runqian's writings, we saw a bottom-class woman in Beijing struggling to survive under the dual pressures of opiate addiction and conflicts between husband and wife. Her experience reflects the hope, pain, hesitation, despair, and choice of bottom-class women in their lives. In recent years, with the continuous in-depth study of social history, gender history, and Beijing history, more and more scholars have begun to pay attention to the suicide of lower-class women during the Republic of China. Regrettably, due to the limitations of historical materials and research horizons, academic research on the suicide of lower-class women in Beijing in the Republic of China is still weak and needs to be further deepened. This article focuses on the archives of the Beijing Municipal Police Department, "Qunqiang Paper" and other local tabloids and social survey reports collected by the Beijing Archives. By restoring the historical reality of the suicide problem of low-level women, this article explores the main reasons for women's suicide, analyzes the modern state power in the early Republic of China and reshapes the life of the bottom society and the coping strategies of ordinary people.

\section{Overview of Women's Suicide}

According to the book "Statistical Map of Beiping Social Survey" by the Peking Institute of Social Research, "In the 1930s, the population structure of Beiping was stable, and young adults accounted for the middle and upper part of the total population. From the perspective of the age distribution of married men and women, Women generally choose to marry between the ages of 15-24, with the largest number of marriages between the ages of 15-19 and about 3000. Men generally choose to marry between the ages of $15-34$, with the most married between the ages of 20-29, about 4000. 1920 The death rate of residents in this city was $22 \%$ in 1930 , and it was 17\% in 1930."[2] Since the police department in Beijing (Ping) in the early Republic of China did not consider population suicide as a separate item of life and death statistics, researchers could not estimate based on this. The total number of suicides by women. When Wang Shi studied the problem of domestic abuse in the bottom society in Beijing from 1914 to 1917 , he found that "In the past four years, there were 32 cases of abuse reported by the Beijing Daily News. Among them, husbands and mothers-in-laws abused their wives in 16 cases, and parents abused and betrayed them. There were 9 cases of children and 7 cases of abuse of apprentices by the master. Except for one case, the victim was a boy, the rest were women, and 5 women committed suicide as a result."[3] Same as "Jinghua Daily", "Qunqiang Paper" Also published a lot of news about the suicide of lower-class women. 
Table 1: Statistics of women's suicides published in "Qunqiang Paper" in 1918

\begin{tabular}{|c|c|c|}
\hline Time & Title & Cause of suicide \\
\hline 1.7 & Saving three people & Poverty \\
\hline 1.8 & Suicide because of emotional problems & Unknown \\
\hline 1.9 & Young woman killed herself & Unknown \\
\hline 2.2 & Young woman drowned herself in a well & Illness \\
\hline 2.3 & Young woman's sati & $\begin{array}{c}\text { To preserve } \\
\text { chastity after the } \\
\text { death of her } \\
\text { husband }\end{array}$ \\
\hline 2.6 & The maid killed herself & Abuse \\
\hline 2.15 & Young woman committed suicide & Unknown \\
\hline 2.22 & $\begin{array}{l}\text { Physical abuse to death (the deceased was her } \\
\text { mother-in-law) }\end{array}$ & Abuse \\
\hline 3.9 & His wife is commendable & Petition \\
\hline 3.9 & Woman hanged herself & Unknown \\
\hline 3.12 & Narrow-minded woman hanged herself & $\begin{array}{c}\text { Trifles (woman } \\
\text { had a quarrel with } \\
\text { her and husband, } \\
\text { mother-in-law, } \\
\text { neighbors, etc. due } \\
\text { to trifles and } \\
\text { committed suicide } \\
\text { in anger) }\end{array}$ \\
\hline 3.12 & Girl took poison & Unknown \\
\hline 3.13 & Woman drowned herself in a river due to poverty & Poverty \\
\hline 3.16 & Young woman committed suicide & Trifles \\
\hline 3.19 & Woman killed herself due to poverty & Poverty \\
\hline 3.22 & Why did she take poison? & Unknown \\
\hline 3.22 & Two cases of being rescued & Poverty and trifles \\
\hline 3.24 & Old woman killed herself & Unknown \\
\hline 4.3 & Young woman took poison & Abuse \\
\hline 4.3 & Young woman committed suicide & Unknown \\
\hline 4.21 & Woman survived after drowning herself in a river & Poverty \\
\hline 4.22 & Young woman cut her own throat & Abuse \\
\hline 4.22 & Saving a woman drowning herself in a river & Poverty \\
\hline 4.26 & Woman drowned herself in a river out of pique & Trifles \\
\hline 5.3 & Young woman took poison & Unknown \\
\hline 5.8 & Young woman drowned herself in a well & Illness \\
\hline 5.9 & Woman survived after drowning herself in a river & Trifles \\
\hline 5.19 & Young woman took poison & Unknown \\
\hline 5.26 & Committing suicide due to poverty & Poverty \\
\hline 6.15 & Woman drowned herself in a river due to poverty & Poverty \\
\hline 6.19 & Saving a woman drowning herself in a river & Illness \\
\hline 6.19 & Woman died of injury & Unknown \\
\hline 6.24 & It was all because of poverty & Poverty \\
\hline 6.26 & Young woman's sati & $\begin{array}{c}\text { To preserve } \\
\text { chastity after the } \\
\text { death of her } \\
\text { husband }\end{array}$ \\
\hline 7.4 & $\begin{array}{c}\text { Woman drowned herself in a river with her } \\
\text { daughter }\end{array}$ & Poverty \\
\hline 7.16 & Woman cut her own throat due to poverty & Poverty \\
\hline 7.16 & Woman cut her own throat due to abuse & Abuse \\
\hline 7.23 & Drowning in a river was miserable & Abuse \\
\hline 8.22 & Being gutted with a knife & Illness \\
\hline 8.23 & Woman drowned herself in a well due to abuse & Abuse \\
\hline 8.26 & $\begin{array}{l}\text { Mother and daughter drowned themselves in a } \\
\text { river }\end{array}$ & Poverty \\
\hline 9.6 & Woman cut her own throat & Trifles \\
\hline 9.29 & Narrow-minded woman drowned herself in a river & Trifles \\
\hline 10.1 & Loyal and valiant woman's sati & $\begin{array}{c}\text { To preserve } \\
\text { chastity after the } \\
\text { death of her } \\
\text { husband }\end{array}$ \\
\hline 10.7 & The whole family took poison & Poverty \\
\hline 10.14 & Young woman committed suicide & Abuse \\
\hline 11.4 & sati & $\begin{array}{c}\text { To preserve } \\
\text { chastity after the } \\
\text { death of her } \\
\text { husband }\end{array}$ \\
\hline 11.21 & The couple drowned themselves in a river & Poverty \\
\hline 12.3 & Woman killed herself because of trifles & Trifles \\
\hline 12.6 & Woman drowned herself in a river due to abuse & Abuse \\
\hline 12.7 & Suicide before marrying & Refusing to marry \\
\hline 12.9 & Taking poison sadly & $\begin{array}{c}\text { To preserve } \\
\text { chastity after the } \\
\text { death of her } \\
\text { husband }\end{array}$ \\
\hline
\end{tabular}

Facing the endless suicides of women, some scholars believe that "Beijing has several suicide incidents in Japan. Examining the reasons for this, difficulties in life are the majority, and the rest of the people who are excited by love are a minority. The weather is warmer than the past, and suicide Suddenly more. According to a group of people who study suicide, suicide has a great relationship with climate..."[4] According to the above table, there were 52 women suicide cases reported by "Qunqiang Paper" throughout 1918. Including 10 in March, the most in the whole year. Except for the two deceased who were old women and the two who were to be married, the rest were all young women who were in marriage. The main reasons that led to women's desperation were poverty (14 cases), abuse ( 9 cases), quarrels ( 8 cases), observance of festivals ( 5 cases), diseases ( 4 cases), etc. There were even several causes caused by extreme poverty. Cases of family suicide or a suicide meeting between a mother and a daughter. This shows that in the early days of the Republic of China, the marriage and living conditions of lower-class women in Beijing were very worrying, and suicide cases were endless.

\section{Analysis of the Causes of Women's Suicide}

In the article "Review of the Causes of Chinese Women Suicide", Yun Shang believes that "Chinese women are far more oppressed than those of the same class because they are under the feudal male-centered family system, coupled with the exhaustion of the rural economy, and the sluggishness of the country. Man. In a normal life, he has accumulated anger, occasionally irritated, and resorted to suicide as a last resort."[5] As an imperial capital of the Yuan, Ming, and Qing dynasties, Beijing used its political, administrative, and ritual functions to compel Established a set of social concepts and life order based on gender[6]. 29 The political and economic transformation in the early days of the Republic of China profoundly affected the overall situation of Beijing's grassroots society and the daily lives of ordinary people. For women living at the bottom of society, this transformation not only provides new opportunities, but also poses serious challenges. Behind the endless suicide cases of women conceal the hardships of low-level women's lives and the difficulties of urbanization.

\subsection{Living in Poverty}

In a suicide case involving a mother-daughter meeting on July 2, 1918, Jia Yuan, who lived in Qitiao Hutong, Deshengmen Inner Street, brought her daughter and son to the Gaoliang Bridge outside Xizhimen to cast the river due to extreme poverty at home. Jia Yuan's daughter and son drowned to death when he was rescued by a passing friend of the Huiyouxuan Teahouse, $\mathrm{Wu} \mathrm{Mou[7].} \mathrm{In} \mathrm{another} \mathrm{case} \mathrm{that}$ occurred in 1942, Zhu Zhang, a 46-year-old woman who lived at No. 8 Neitangzi Alley, Xiangbai Hutong, Beixinqiao, had 8 children. Frequent births caused her to suffer from various diseases. Although his husband Zhu Diankui makes a living running a barber shop, his family has been unable to make ends meet for a long time and lives in extreme poverty. Under the double torment of poverty and disease, Zhu Zhang, who 
was so desperate, ended his life with a razor[8]. In the 15th year of the Republic of China (1926), the Jingshi Police Department put forward in the winter social survey report:

"Beijing's urban and suburban areas total 254,382, of which 66,603 are poor households, accounting for $2 \%$ of the total. Among the poor, there are 42983 extremely poor households, accounting for 17\%; sub-poor households, 22620, accounting for $9 \%$; inferior The number of households is 120,437, accounting for $4 \%$ of the total number of households; the total number of lower and poor households is 187,040 , accounting for $73 \%$ of the total number of households."[9]

For the low-income and poor households accounting for $73 \%$ of the total number of households, the long winter and the weak social relief system have greatly weakened their desire to survive. For the women in these families, even though they have successfully transformed the urban public space into a daily life space through their own efforts, they do everything possible to make a living and enjoy themselves on the street, and meet the minimum survival needs[6]. However, there are still some women, especially those who are widowed or have many children, who have no way of supporting themselves, and they have only died of liberation.

\subsection{Family Conflicts}

On the evening of November 16, 1916, Wang Cao, who lived in Niuquan Hutong, had a quarrel with his sister Xin Cao because of housework. Angrily, Xin Cao tried to commit suicide and swallowed a pair of small golden pliers and a large amount of lead powder. Under the multiple treatments of Police Constable Li Dexu, Judicial Inspector Jin Changqing, and doctors at the Presbyterian Hospital for Women and Infants, he believed that Cao's crisis was turned into peace[10]. In another case, $\mathrm{Hu}$, who lives in Huguosi Street, relied on family wealth, met a daughter outside marriage, and eloped as a concubine. His concubine had a wicked personality, and was treated by $\mathrm{Hu}$ in all manners, and with the secret support of Hu's mother, he "beaten and scolded and humiliated his wife all day long and was totally unreasonable." In the face of serious family conflicts, the wife of a certain family was so desperate that she decided to take poison and commit suicide. According to the "Beijing Daily" report, "(A certain family member was suffering from a stomachache after swallowing the poison), and she wailed loudly. Her neighbors all heard about it. Her mother and son were so panicked. She was taken to the hospital and died. Everyone saw that the clothes of the deceased had been torn to pieces, the lower part was dripping with blood, and the shape was extremely miserable."'[11] According to the "Temporary New Criminal Law of the Republic of China", "the murderer shall be sentenced to death, life imprisonment or first-class imprisonment... Those who commit suicide or kill with their promise are sentenced to second to fourth class imprisonment."[12] Although the Jingshi Police Department received a report from Hu's neighbor, it did not initiate further investigations. The reason may be as stated in the "Beijing Daily News", "Hu Mou was sent out of the city secretly for fear of his concubine being involved...(his wife)'s family is a countryman, so if you give it a little bit of money, you can't say anything.”[10]

Ma Zhao believes, "In the face of poverty, women can rely on labor in exchange for food and clothing, but the more common choice is to rely on their husbands to solve their difficulties in life through marriage.'[13] 158 But this hastily established because of material life. Marriage lacks a solid emotional and economic foundation, and is often reduced to a simple relationship of resource exchange and livelihood cooperation. When investigating the family life of the poor in Beijing, Gambo found that a rickshaw driver's family with a monthly income of only 17 yuan spent 61.1 yuan for their daughter's wedding. In addition to the wedding guests' income of 32.7 yuan, they also need to borrow 24 yuan to fill the shortfall[14]. For the poor, this "money uneconomical" wedding not only means the conclusion of a marriage relationship, but also represents a powerful social authority. Through the wedding, the newlyweds present their marriage relationship in front of their family members, other community residents, and neighbors in the compound. The recognition of the marriage relationship and the status of the husband and wife by the relatives and neighbors of both parties becomes the cultural prerequisite for the newlyweds to live, live, and socialize in the community in the future[13]. 173 For lower-class women, this kind of marriage means that she breaks away from her original family and enters a social network composed of her husband's relatives and husband's neighbors. Once this kind of marriage relationship that lacks a stable relationship and economic foundation has problems, it is difficult for women to obtain protection from the husband's family. Instead, they will be restricted by the social concept of fulfilling the wife's obligation to repay the living resources provided by the husband's family. Faced with this predicament, the isolated and helpless women have to seek relief through suicide.

In the case of Chen Chunyao's wife Chen Hou's suicide with a knife on December 31, 1927, the confessions of her husband Chen Chunyao, wife Chen Hou, and sister-in-law Chen Zhang clearly reflected the low-level women's behavior in the face of the authority of the husband's family. Distress and helplessness. At about 2 pm that same day, Chen Chunyao, who lives at No. 66 Zhuanta Hutong, reported to the 14th Police Station of the Beijing Normal Police Department, saying that his wife Chen Hou had cut her neck with a razor at home and was seriously injured. He asked for medical treatment. Police officers Wen Rui and Zhu Shiying arrived at the scene and found that "Chen Hou's family was lying on the Beijian Kang, with a lot of blood stains and breath, but his injuries were serious and he could no longer speak."[15] After emergency rescue by the Central Hospital, Chen Hou was out of danger and explained the reason for the suicide to the police:

"My sister-in-law abused me so much. Every day I didn't ask me to go to bed until three or four o'clock in the night (page 2), and asked me to get up early in the morning, and asked me to eat after two meals a day, until I had a meal. It was cold. The day before I wiped myself, due to pneumothorax pain, I didn't 
eat a day. At four o'clock in the night, my sister-in-law asked me to go back to bed and I would lie down. My sister-in-law called me again. My husband went over. My sister-in-law was angry and made my husband beat me, but my husband refused. The next morning my sister-in-law stopped asking me to clean up the house for her. I feared that my sister-in-law would offend my husband, so I wiped my neck with my husband's razor, Jitu will die...’[15]

Faced with Chen Hou's allegations, his sister-in-law Chen Zhang denied that she had committed abusive behavior:

"I was unable to get up on the sixth day of the lunar month due to illness. On the seventh day of the month, I recovered a little. I wanted to eat porridge and asked my brother to cook it. My brother didn't want to make it. I can't go to persuade me. On the morning of the 8th day, I heard my brother yell that my brother wiped his neck by himself before I got up. I got up and took care of him. It is now being summoned that I have not abused my brother's wife."[15]

The husband of Chen Hou's Chen Chunyao believes that the wife's suicide was caused by a quarrel between the husband and wife over household chores last night. But what is unusual is that when he found out that Chen Hou had committed suicide in the early morning, what he did the first time was not to rescue his wife, but to "go to Cai Huzhuang outside Pingze to send a letter to her family." It was not until 1 p.m. when he returned home that he found his wife "still alive", and then went to the police station to report[15].

Through the client's confession, it can be found that Chen Hou's long-term abuse by his sister-in-law and neglect by her husband has caused a very serious pessimism. However, under the influence of traditional Chinese hierarchy, Chen Zhang did not believe that his abusive behavior led to the suicide of his sister Chen Hou. As a representative of the authority of her husband's family, when Chen Chunyao faced his wife's suicide, the first thing he thought of was how to use his authority to calm the situation through Chen Hou's parents. For Chen Chunyao and Chen Zhang, the starting point of all their actions is not to protect the Chen Hou, who is in a disadvantaged position, but to maximize advantages and avoid disadvantages.

\subsection{Traditional Ideas}

In the article "Review of the Causes of Chinese Women Suicide", Yun Chang pointed out that "Chinese women still regard widowhood as their virtue after the death of their husbands, under the supervision of public opinion. Their feelings for widowhood are hardship without the courage and opportunity to remarry or commit adultery. Widows still often hear about suicide."[5] A case like this was published in the "Qunqiang Paper" on October 1, 1918, "The Five Holy Temples in the South of Youanmen, and the son of Li Jinshan, a farmer, is named Jinshou, Nian Twenty-two years old, he was doing business in a foreign goods store in the city. A few days ago, he returned home due to illness, the treatment was ineffective, and passed away. Yi's wife $\mathrm{He}$, only nineteen years old, found a short-lived husband, and his family's feelings. I have already died of anger. Neighbors and rightists heard about it, and they all sighed.'[16] Even though some of the new-style intellectuals working in Beijing universities at this time are vigorously advocating the family revolution and advocating the liberation of women. But as Zhang Xichen said, "Although ordinary young people know that the family system is extremely difficult to maintain and feel the pains of the old family life, since one party wants to declare war with the opponents, the other party is even more difficult to proceed. Therefore, the argument of family revolution has been sung. For many years, there is still no achievement to say."[17] For the women at the bottom, they have no chance to accept the influence of the thought of family revolution. Under the double blow of the concept of keeping the festival and the lack of livelihood, they can only be relieved by death.

If the suicide caused by martyrdom is an extreme case, then the traditional concepts such as the inferiority of men and the inferiority of women in the daily life of low-level women, and the traditional concepts of "wife-in-law become wives for many years" have gradually weakened their confidence in married life. In the case of Lian Ma's suicide by taking poison in May 1915, the deceased had a long-term quarrel with her husband and mother-in-law. According to Lian Ma's mother-in-law, Lian Gao's confession, “On March 20th, because my son and wife did not pull their hair and did not listen to teachings, I hit him on both mouths with my hands."[18] It means that as a mother-in-law, Lien Gao deserves unquestionable status and power. The disheveled behavior of her daughter-in-law seriously violated her authority as a mother-in-law and should be punished. For Lian Ma and many lower-class women, the abuse of mother-in-law and neglect of husband constitute the last straw that overwhelms their lives.

\section{Governance of Women's Suicide}

Faced with the endless suicides of women in the Republic of China, the author of the pen name Shi believes that the government can manage it by strengthening marriage legislation, promoting social relief, and establishing a compulsory education system[19]. However, as Ma Zhao observed when examining the marriage management system and regulations of the Nationalist Government in the 1930s and 1940s, "From the perspective of the concept of marriage reform propagated by the state, the marriage custom left over from the reform empire has become a state and Intellectuals have a consensus, but in the implementation of specific measures for marriage reform, the state seeks a middle way."'13] 216 In Beijing society in the early days of the Republic of China, the Jingshi Police Department, the Infantry Commander Yamen, and the Jingzhaoyin Office, etc. The police agency did not force the implementation of a series of new marriage management systems, but instead formulated open supervision rules to accommodate a variety of marital status[13]. 216 Regrettably, when dealing with marital crises and women's suicide, these regulatory rules are difficult to play their due role. 
In October 1916, the Jingshi Police Department, the Infantry Commander Yamen, and the Jingzhaoyin Office jointly promulgated the "Joint Signing Proclamation on the Prohibition of Suicide Cases on the Rise":

"For the purpose of publicity, investigations have recently been heard about cases of suicide reported on the ground inside and outside Beijing, and most people wiped themselves with a razor. The reason is that because family education is ignored, the people's knowledge is mediocre." Every time a small indignation leads to a suicide. As a parent, he is usually unable to correct himself and lead others, and he cannot mediate and prevent any incidents. At the same time, he can store poison and sharp weapons at his discretion. An occasional encounter with Boxi will result in a murder, which is good and pitiful. The government office and yamen have the responsibility to defend the people, and it is urgent to persuade residents and others to be aware of it. The housekeeping is based on diligence, thrift and peace, and the education of the children is based on ethics and morality. If the personality is progressive and complete, life is precious with knowledge and self-defeating The case should be tacitly invisible. As for toxic substances and razors and other devices, households should not purchase and store them at home, in order to prevent danger and be humane. In addition to paying attention to persuasion by the military and police affiliated to Tongfu, the residents should be informed about this. Hereby announce."'[20]

The bulletin attributed the high incidence of suicide cases to the lack of family education, stating that male parents "neither have the ability to correct themselves and lead others, nor can they mediate and prevent them in case of incident, and store poisons and weapons freely". Parents are urged to uphold the "diligence, thrift and peace" principle of family management and to educate their wives, sons and daughters with "ethical morality" so as to achieve the ideal state of "the case of suicide, the invisible". But for women at the bottom, neglect, abuse and violence from male parents are often the main reasons leading to their suicide. Although the police in various jurisdictions can "pay attention to persuasion", they are often after the fact counseling and criminal investigations, which are not helpful in reducing the risk of women's suicide. For example, in the case of Du Feng's suicide by swallowing morphine due to housework in November 1926, the focus of the police was not on how to solve the serious family conflicts in Du's family, but to interrogate her "Where does the driver who bought the morphine live?" Where can I buy morphine?" and "send detectives to investigate the morphine shop."[21]

For women at the bottom, when they face the interrogation of the police agency and enter a space woven by state power and male authority, they often find ways to conceal their real experience. This phenomenon was clearly manifested in the case of Feng Zhang's abusing his daughter-in-law, Qing Rui, in July 1914. According to a report by the Beijing Daily:

"Beixinqiao Dachang (Guangchao) Yulingkeng lives in Fengmou who sells water and rice. I married a daughter-in-law last year. After passing the door, Fengmou's wife and daughter-in-law, not one day (beat) daughter-in-law. Now Her daughter-in-law, who is already pregnant, is still beaten up in the sky, and the neighbors nearby are all gnashing their teeth. If you have the responsibility to defend the lives of the people, why not intervene at once.’[22]

In the face of police inquiries, Qing Ruishi insisted, "I have been through the house since I was 16 years old. So far, I have not been beaten or abused by my mother-in-law. Okay."[22] Feng Zhang also said, "I have not abused my daughter-in-law, and she also confessed that she has never been beaten or scolded by me. If the department later finds out that I have the previous affair and newspaper auspicious signs, I am willing to accept heavy punishment.'[22] Unfortunately, according to the existing historical data, we cannot restore the real experience of Qing Ruishi. However, it is not difficult to see from the two apparently contradictory materials that in the face of unfamiliar state power, traditional concepts such as "family shame must not be publicized" often become ideological resources that dominate the actions of women at the bottom. They do not understand and cannot trust the new marriage management system promoted by the government, and they cannot take the initiative to obtain protection from the police. Although local governments have worked hard to incorporate marital crisis and women's suicide into the scope of social intervention by police agencies, there is always a huge tension between policy and practice, and the marriage and life conditions of women at the bottom are not optimistic.

\section{Conclusion}

James Scott once described the rule of the pre-modern state in this way, "In many ways, the pre-modern state is in a state of 'semi-blindness'. Little is known about the geographical distribution of properties and property, as well as personal information. However, modern countries have tried and achieved varying degrees of success, reshaping its territory and people with a standardized model, so that the government can implement monitoring, liquidation, evaluation, and management.'[23] Marriage management constitutes the basic cognition of the modern state of the society and people under its management. Although local governments are striving to implement a set of marriage management systems that meet the requirements of the modern state, they consciously and step by step extend the state's control power to the grassroots society, and gradually incorporate the daily lives of ordinary people into their own supervision. But women at the bottom still suffer severe gender oppression in their married life. The poor living environment, stereotyped traditional concepts, and indifferent family relationships have greatly weakened their confidence in survival, and suicide cases have emerged one after another. When dealing with such cases, the government is often in a passive position, and it is difficult to prevent them from the source. From the Du Feng family, the Lian Ma family, and the Chen Hou family who are on a dead end, we can see a country that constantly reconciles the contradictions between the ruling ideals and the social reality. For the bottom women who are in a state of despair, only a thorough social revolution can clean up the dust and achieve true liberation. 


\section{References}

[1] Submission of the Central District Office of the Beijing Police Department on the suicide of Zhang Mingshan's wife[Z]. 1918, Beijing Municipal Archives, J181-01822352.

[2] Beiping Social Research Institute. Statistics of Beiping Social Profile[A]. Selected by the National Library. Collection of Social Survey Materials during the Republic of China[M]. Beijing: National Library Press, 2013: 8-10.

[3] Wang Shi. Domestic Abuse in the Legal System and Social Consciousness in the Early Republic of China-Based on the Abuse Cases in the "Jinghua Daily" from 1914 to $1917[\mathrm{~J}]$. Sun Yat-sen University Law Review, 2010(1): 64-66.

[4] Beijing's suicide is invincible[N]. Republic of China Daily, 1922-04-18, (2).

[5] Yun Shang. A review of the causes of suicide among Chinese women[J]. Women's Resonance Monthly, 1934(11):17.

[6] Cheng Weikun. Working Women: Beijing's Urban Space and the Daily Life of Women at the Bottom in the Early 20th Century[M]. Yang Ke, Beijing: Life-Reading.Xinzhi Sanlian Bookstore, 2015.

[7] Meng Zhaochen. The first series of tabloids from all over China in modern times (Volume 26)[M]. Beijing: Xueyuan Publishing House, 2010: 472.

[8] Beijing Women's Society: Suicide due to procreation[J]. Women's Journal (Beijing), 1942(5): 46.

[9] Li Jinghan. Discussion on the minimum living standards in Beiping[J]. Sociology, 1929(3): 3.

[10] Submission of the District Office of the Third District of the Left in the Beijing Police Department regarding the rescue of Xin Cao's suicide by swallowing lead powder[Z]. 1916, Beijing Municipal Archives, J181-018- 06309.

[11] Jingshi Police Department's article on a piece of abuse and suicide in the "Jinghua Daily" in the third district of the right of Zhannei[Z]. 1914, Beijing Municipal Archives, J181-018-01561.

[12] Ministry of Justice. The Provisional New Criminal Law of the Republic of China[M]. Shanghai: Guangyi Bookstore, 1912: 60-61.

[13] China University of Political Science and Law Research Institute of Ancient Books of Law. The judicial archives of the Republic of China in Qing Dynasty and the legal system in Beijing[M]. Beijing: China University of Political Science and Law Press Co., Ltd., 2014: 158.

[14] Sydney Gamble: How Chinese Families Live in Peiping: A Study of the Income and Expenditure of 283 Chinese Families Receiving from MYM8 to MYM550 Silver per Month[M]. New York: Funk \& Wagnalls company, 1933: 220- 221.

[15] Submission of the District Office of the Second Right District of the Beijing Police Department on the case of Chen Chunguang's wife Chen Hou's suicide with a knife[Z]. 1928, Beijing Municipal Archives, J181-02000046.

[16] Meng Zhaochen. The first series of tabloids from all over China in modern times[M]. (Volume 28). 2010: 24.
[17] Selu. Family Innovation Theory[J]. Women's Journal, 1923(9): 11.

[18] Details of the case of Lien Ma's suicide suicide by his daughter-in-law against Ma Changshun in the Third Right District Office of the Beijing Police Department[Z]. 1915, Beijing Municipal Archives, J181-019-09779.

[19] Shi. From the causes of women's suicide to the methods of relief[J]. Saturday, 1933(532):669.

[20] Infantry Commander Yamen's Letter on Prohibiting the Rise of Suicide Cases and Proposing to Issue a Joint Signed Announcement[Z]. 1916, Beijing Archives Collection, J181-018-07352.

[21] The District Office of the First District on the right outside the Beijing Police Department regarding Du Feng's suicide by swallowing morphine due to quarrels at home[Z]. 1926, Beijing Municipal Archives, J181-018-18930.

[22] Jingshi Police Department's “Jinghua Daily" article on the abuse of a daughter-in-law[Z].1914, Beijing Municipal Archives, J181-018-01517.

[23] James Scott, Seeing Like a State: How Certain Schemes to Improve the Human Condition Have Failed[M]. New Haven: Yale University Press, 1998: 2. 